\title{
Innovation implementation in the context of hospital QI: lessons learned and strategies for success
}

This article was published in the following Dove Press journal: Innovation and Entrepreneurship in Health

\author{
Pavani Rangachari \\ College of Allied Health Sciences, \\ Augusta University, Augusta, GA, USA
}

\begin{abstract}
In 1999, the Institute of Medicine (IOM) reported that 98,000 people die each year due to medical errors. In the following years, the focus on hospital quality was intensified nationally, with policymakers providing evidence-based practice guidelines for improving health care quality. However, these innovations (evidence-based guidelines) that were being produced at policy levels were not translating to clinical practice at the hospital organizational level easily, and stark variations continued to persist, in the quality of health care. Circa 2009, nearly a decade after the release of the IOM report, the health care organizational literature began referring to this challenge as "innovation implementation failure" in health care organizations (HCOs), ie, failure to implement an evidence-based practice that is new to a HCO. This stream of literature drew upon management research to explain why innovation implementation failure occurs in HCOs and what could be done to prevent it. This paper conducts an integrative review of the literature on "innovation implementation" in hospitals and health systems over the last decade, since the spotlight was cast on "innovation implementation failure" in HCOs. The review reveals that while some studies have retrospectively sought to identify the key drivers of innovation implementation, through surveys and interviews of practitioners (the "what"), other studies have prospectively sought to understand how innovation implementation occurs in hospitals and health systems (the "how"). Both make distinctive contributions to identifying strategies for success in innovation implementation. While retrospective studies have helped identify the key drivers of innovation implementation, prospective studies have shed light on how these drivers could be attained, thereby helping to develop context-sensitive management strategies for success. The literature has called for more prospective research on the implementation and sustainability of health care innovations. This paper summarizes the lessons learned from the literature, discusses the relevance of management research on innovation implementation in HCOs, and identifies future research avenues.

Keywords: innovation implementation, change implementation, health care organizations, hospitals and health systems, implementation science, quality improvement, evidence-based practice guidelines, evidence-based management
\end{abstract}

\section{Introduction}

In 1999, the Institute of Medicine (IOM) issued a landmark publication, which reported that 98,000 people die each year due to medical errors, costing the nation billions of dollars per year. ${ }^{1}$ In the following years, the focus on hospital quality and safety was intensified, with researchers demonstrating the scope and potential for preventing adverse events and other complications like hospital-acquired infections (HAIs), across the nation. Importantly, this type of evidence prompted our nation's leading health care quality institutions like the Institute for Healthcare Improvement (IHI),
Correspondence: Pavani Rangachari Augusta University, 987 St. Sebastian Way, EC-34I4, Augusta, GA 30912, USA

Tel +l 70672 I 2622

Email prangachari@augusta.edu 
the Joint Commission, the National Quality Forum, and the Agency for Healthcare Research and Quality (AHRQ) to develop evidence-based practice guidelines (eg, the Central Line Bundle [CLB]), launch far-reaching patient safety initiatives (eg, the IHI 5 Million Lives Campaign), and generate impactful reports (eg, AHRQ's National Healthcare Quality Reports). ${ }^{2,3}$ These efforts in turn coincided with numerous private and public payer initiatives to publicly report on hospital quality measures, for example, the Center for Medicare \& Medicaid Services (CMS) "Hospital Compare" initiative paved the way for the ongoing pay-for-performance and value-based hospital reimbursement initiatives of CMS, all within a decade of publication of the 1999 IOM report. ${ }^{4}$

Despite the substantial momentum toward hospital quality at the policy level, the progress made at the hospital organizational level, even a decade after the release of the IOM report (circa 2009), was deemed to be extremely slow. ${ }^{3,5}$ In other words, the innovations (eg, evidence-based practice guidelines) that were being made at academic and policy levels were not translated to clinical practice easily or completely at the hospital level. For example, researchers at the Leapfrog Group surveyed over 1,200 hospitals and reported that $87 \%$ of hospital employees were not following the recommendations for preventing HAIs, including hand hygiene guidelines. ${ }^{5}$ In a similar vein, the AHRQ National Healthcare Quality Report showed only a marginal annual average improvement of $1.5 \%$ in 15 quality measures, nearly a decade after the release of the IOM report. ${ }^{3}$

Around the same time (circa 2009), the health care organizational literature began referring to the challenge of lagging quality of health care in the USA, as "innovation implementation failure" in health care organizations (HCOs), ie, failure to implement an evidence-based practice that is new to the organization. ${ }^{6}$ The slow progress with quality improvement in the health care industry was a sharp contrast to progress made in other industries like automotive manufacturing, which strives to improve the service quality every year. The sluggishness at the HCO level was particularly striking in light of the increasing availability of evidence-based practices for improving patient outcomes and the growing momentum toward public reporting of hospital quality.

The health care organizational literature put forth that a likely explanation for this phenomenon is that HCOs fail to implement innovations well. ${ }^{6-8}$ For example, in the context of implementing clinical practice guidelines, a potential implementation failure in HCOs may be only partial compliance with the evidence-based guidelines. Similarly, in the context of implementing electronic health records, potential implementation failures may be lack of adoption by physicians, less-thanadequate support for changing the workflow, and absence of standardization. In the context of implementing error reporting systems, HCOs may experience incomplete reporting of errors or generally not use the system consistently. ${ }^{8-10}$

In light of these observations, nearly a decade after the release of the 1999 IOM report, a stream of health care organizational literature drew upon management research, to explain why innovation implementation failure occurs in HCOs and what could be done to prevent it. ${ }^{6-24}$ Table 1 outlines the main tenets of the literature on "innovation implementation failure" in HCOs. As shown in Table 1, in the decade following the release of the 1999 IOM report, the health care organizational literature used management research to explain both why "innovation implementation failure" occurs in HCOs (in the context of health care quality) and what could be done by HCOs to prevent them.

\section{Purpose and objectives}

The spotlight on "innovation implementation failure" in HCOs in circa 2009 in turn prompted several health care organizational researchers to pay attention to the topic in the subsequent years. The purpose of this paper is to understand if the generic insights from management research have been relevant to addressing the challenge of innovation implementation in hospitals and health systems, over the past decade. If so, has the research identified specific evidence-based management strategies for success with innovation implementation in hospitals and health systems? If not, what are the gaps in the literature, and how could they be addressed? The focus on hospitals and health systems in this review in turn, stems from the fact that the IOM report of 1999 paid special attention to the problem of medical errors in US hospitals and that a vast proportion of subsequent US health policy initiatives were directed toward hospital organizations, including inpatient, outpatient, and primary care settings for acute, chronic, and primary care services. Therefore, the purpose of this paper lies in reviewing and critiquing the progress that has been made with "innovation implementation" in hospitals and health systems over the last decade, ever since the spotlight was cast on "innovation implementation failure" in HCOs.

The objectives of this paper are as follows:

1. Conduct an integrative review of the literature on "innovation implementation" in hospitals and health systems over the past decade, to summarize the lessons learned with 
Table I Insights from management research on "innovation implementation failures" in health care organizations (HCOs) in the context of health care quality improvement

\begin{tabular}{|c|c|c|}
\hline $\begin{array}{l}\text { Why do "innovation implementation failures" } \\
\text { occur in HCOs? }\end{array}$ & $\begin{array}{l}\text { What could be done to prevent "innovation } \\
\text { implementation failures" in HCOs? }\end{array}$ & References \\
\hline $\begin{array}{l}\text { Nature of work in HCOs involves uncertainty and } \\
\text { risk of patient fatality and entails considerable clinician } \\
\text { discretion. Clinicians are averse to experimenting with } \\
\text { new ways to deliver care since it could be risky to the } \\
\text { patient. As such, clinicians have the liberty to avoid } \\
\text { innovation implementation. }\end{array}$ & $\begin{array}{l}\text { Clinician resistance to participate in implementation efforts } \\
\text { could be overcome by enabling them to try out innovations in } \\
\text { ways that are not threatening, like pilot studies or dry runs. } \\
\text { Such opportunities could provide low-risk scenarios where } \\
\text { failures do not impact patients. }\end{array}$ & $6-18$ \\
\hline $\begin{array}{l}\text { Workforce characteristics in HCOs include a } \\
\text { strong specialized and hierarchal culture governing } \\
\text { interpersonal interactions. Correspondingly, there } \\
\text { is a strong professional identification. This results } \\
\text { in limited collaboration among clinicians and limited } \\
\text { organizational identification (both of which are crucial } \\
\text { for innovation implementation). }\end{array}$ & $\begin{array}{l}\text { Leaders must frame the implementation effort as a "learning } \\
\text { challenge," rather than a "performance challenge," to encourage } \\
\text { interprofessional collaboration. Also, leaders must increase } \\
\text { organizational identification by enabling clinicians to perceive } \\
\text { alignment between their goals and values and organizational } \\
\text { goals and values. }\end{array}$ & 19,20 \\
\hline $\begin{array}{l}\text { Leader-workforce relations in HCOs are such that } \\
\text { leaders have limited control over health professionals, } \\
\text { resulting in "transactional" this-for-that exchanges; } \\
\text { as such, leaders and workforce are unable to place } \\
\text { collective goal (innovation implementation) above } \\
\text { self-interest. }\end{array}$ & $\begin{array}{l}\text { Leaders must incorporate "transformational leadership" } \\
\text { processes to shift clinicians' focus from individual goals to } \\
\text { collective goals, ie, innovation implementation. Transformational } \\
\text { leaders are intellectually stimulating and can motivate health } \\
\text { professionals to consider how their own individual goals overlap } \\
\text { with the collective goals. }\end{array}$ & $|2,2|$ \\
\hline $\begin{array}{l}\text { Performance measurement and control systems in } \\
\text { HCOs are underdeveloped; it has been a challenge } \\
\text { to design and develop valid and reliable measures } \\
\text { of quality; underdeveloped measurement systems } \\
\text { deprive HCOs of crucial performance data for } \\
\text { monitoring implementation efforts. }\end{array}$ & $\begin{array}{l}\text { Leaders must involve workforce in development of the } \\
\text { measurement, share authority in decision-making over } \\
\text { components of the system, engage health professionals } \\
\text { through ongoing communication, and measure and reward } \\
\text { implementation efforts. Since innovations call for clinician } \\
\text { interdependence to perform tasks, incentives provided at the } \\
\text { group-level may work better compared to the individual level. }\end{array}$ & $22-24$ \\
\hline
\end{tabular}

respect to innovations of interest, care settings, theoretical frameworks, methodologies, and findings (ie, empirical evidence) on innovation implementation.

2. Identify strategies for success with innovation implementation in hospitals and health systems.

3. Discuss the relevance of management research for addressing the challenge of innovation implementation in hospitals and health systems.

4. Articulate gaps in the literature, and discuss future research avenues on innovation implementation in hospitals and health systems.

\section{Literature on "innovation implementation" in hospitals and health systems Scope and focus of integrative review of literature}

The purpose of this paper was to review the literature on "innovation implementation" in hospitals and health systems over the past decade, since the spotlight was cast on the challenge of "innovation implementation failure in health care organizations (HCOs)" in circa 2009, by a spate of articles in health care organizational journals (referenced in Table 1). As discussed earlier, the broader context for this literature was the lagging quality of health care in HCOs, nearly a decade after the release of the 1999 IOM report on medical errors. In essence, this stream of literature drew upon management science to explain why "innovation implementation failure" occurs in HCOs and what could be done to prevent it.

Innovation implementation in HCOs refers to the implementation of anything that is new to the $\mathrm{HCO}$, be it an evidence-based practice, policy, or technology (within the context of health care delivery). This topic would come under the broader subject area of "implementation science in health care," a nascent yet growing stream of literature. Within this broad and diverse subject area, the focus of this review is on the line of inquiry specific to "innovation implementation" in HCOs, since 2007, with a further focus on hospitals and health systems, and within the context of quality of health care in the USA, under the backdrop of the landmark IOM report of 1999 . 
Since the focus of this review is on identifying articles that sought to understand implementation of a new practice (or a changed practice) in HCOs, "change implementation" was identified as an appropriate supplemental keyword to use alongside "innovation implementation" in the initial search for articles. Correspondingly, a keyword search on "innovation implementation"[All Fields] OR "change implementation"[All Fields] was conducted on PubMed/ MEDLINE and NCBI databases. The search resulted in an initial set of 125 articles. As a first step, the abstracts and titles of these articles were screened, and articles were excluded, if they were 1) not based in hospitals and health systems, 2) not published during or after 2007, and 3) not based in USA or developed nations. Next, the full texts of the remaining articles were assessed, and articles were excluded, if the topic did not pertain to the quality and delivery of health care. Figure 1 provides a flowchart of the article selection process, which helped whittle down the initial set of 125 articles to a final base of 50 articles for review. ${ }^{18,25-74}$

\section{Retrospective versus prospective articles on innovation implementation in hospitals and health systems}

Table 2 summarizes the key characteristics of the 50 reviewed articles in regard to innovations of interest, care settings, theoretical frameworks, and methodologies. As indicated on Table 2, of the 50 reviewed articles, 11 were non-empirical articles (eg, reviews or theoretical articles), while 39 were empirical articles (involving data collection and/or analysis). A full review of the 39 empirical articles, helped classify these articles into two broad categories:

1. Retrospective articles seeking to understand the key drivers of innovation implementation at organizational and/or clinician levels, after the conclusion of an implementation effort (the "What").

2. Prospective articles seeking to understand how innovation implementation occurs at an organizational and/or clinician levels, from onset to completion of an implementation effort (the "How").

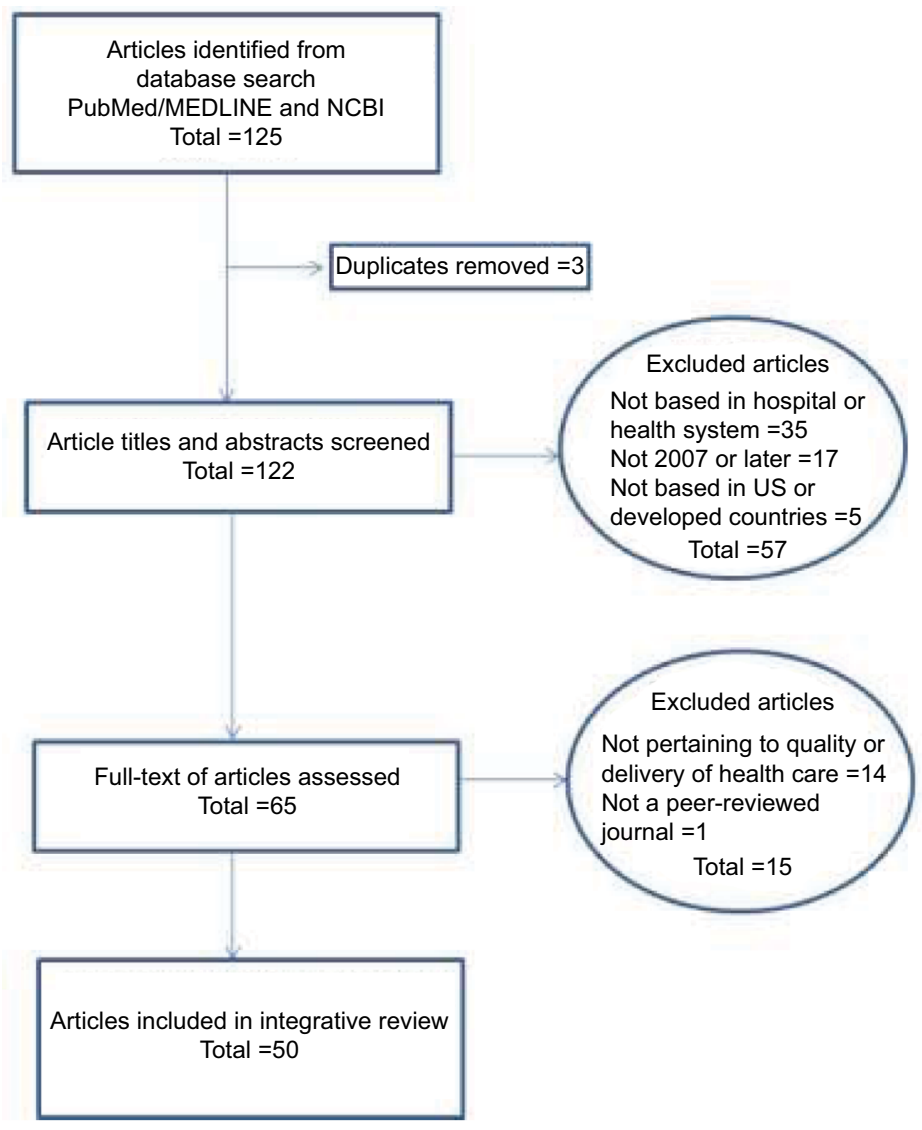

Figure I Flowchart of article selection process for integrative review. 
Table 2 Characteristics of reviewed articles

\begin{tabular}{|c|c|c|}
\hline Characteristic (variable) & Type (value) & $\begin{array}{l}\text { Numeratorl } \\
\text { Denominator (\%) }\end{array}$ \\
\hline \multirow[t]{6}{*}{ Innovations of interest } & Evidence-based practice guidelines & $12 / 50(25 \%)$ \\
\hline & Patient safety protocols & $\mathrm{I} \mathrm{I} / 50(23 \%)$ \\
\hline & Health IT & $9 / 50(18 \%)$ \\
\hline & Patient-and-family-centered care & $5 / 50(10 \%)$ \\
\hline & Chronic disease management & $6 / 50(12 \%)$ \\
\hline & Other & $5 / 50(10 \%)$ \\
\hline \multirow[t]{4}{*}{ Care setting } & Hospital-inpatient (including emergency, medical/surgical, intensive care unit, etc) & $21 / 50(4 \mid \%)$ \\
\hline & Outpatient-subspecialty (eg, cardiology, oncology) & $9 / 50(18 \%)$ \\
\hline & Outpatient-primary care & $6 / 50(12 \%)$ \\
\hline & Health system (including Veterans Affairs)-multiple care settings & $14 / 50(28 \%)$ \\
\hline \multirow[t]{2}{*}{ Article type } & Empirical (involving data collection and/or analysis) & $39 / 50(78 \%)$ \\
\hline & Non-empirical (review, discussion, conceptual, or theoretical) & $\mathrm{I} \mathrm{I} / 50(22 \%)$ \\
\hline \multirow{13}{*}{$\begin{array}{l}\text { Theoretical frameworks used in } \\
\text { empirical articles }\end{array}$} & Innovation Implementation Framework & $8 / 39(21 \%)$ \\
\hline & Barriers Scale & $1 / 39(3 \%)$ \\
\hline & Middle Managers Role in Innovation Implementation & $6 / 39(15 \%)$ \\
\hline & Disruptive Innovation Theory & $1 / 39(3 \%)$ \\
\hline & Diffusion of Innovation Theory & $1 / 39(3 \%)$ \\
\hline & Systematizing Person-Group Relations Framework & $1 / 39(3 \%)$ \\
\hline & Deskilling Type Adaptation Model & $1 / 39(3 \%)$ \\
\hline & Sense-Making Theory & $1 / 39(3 \%)$ \\
\hline & Innovation Complexity Framework & $1 / 39(3 \%)$ \\
\hline & Organizational Learning & $1 / 39(3 \%)$ \\
\hline & Organizational change (planned vs emergent change) & $2 / 39(5 \%)$ \\
\hline & Professional Complex Systems Framework & $5 / 39(12 \%$ \\
\hline & No theoretical framework used & $10 / 39(26 \%)$ \\
\hline \multirow{3}{*}{$\begin{array}{l}\text { Study designs used in empirical } \\
\text { articles }\end{array}$} & Retrospective cross-sectional studies (e.g., surveys \& interviews) & $24 / 39(62 \%)$ \\
\hline & Restrospective case studies & $9 / 39(23 \%)$ \\
\hline & Prospective studies & $6 / 39(15 \%)$ \\
\hline \multirow{6}{*}{$\begin{array}{l}\text { Data collection methods used in } \\
\text { empirical articles }\end{array}$} & Mixed methods & $24 / 39(62 \%)$ \\
\hline & Surveys & $4 / 39(10 \%)$ \\
\hline & Interviews and/or focus groups & $6 / 39(15 \%)$ \\
\hline & Content analysis & $2 / 39(15 \%)$ \\
\hline & Archival and/or secondary data analysis & $1 / 39(3 \%)$ \\
\hline & Other qualitative techniques & $2 / 39(5 \%)$ \\
\hline
\end{tabular}

This broad classification of articles into retrospective versus prospective is highly relevant for the purpose of this review, since a key objective is to identify strategies for success with innovation implementation. An important gleaning from the review was that many articles sought to identify the key factors driving innovation implementation retrospectively, through surveys and interviews with implementation champions or health care leaders, following a completed implementation effort. On the other hand, a fewer number of articles sought to prospectively understand how innovation implementation occurs within the context of a hospital or health system, by observing the unfolding of an implementation effort, with special attention to factors enabling success with innovation implementation.

Both the approaches have made significant contributions to identifying strategies for success with innovation implementation. However, a key distinction is that while retrospective studies have helped to identify the key drivers for innovation implementation (the "What"), like "presence of a champion," "innovation-values fit," etc., prospective studies have shed light on how these drivers could be attained (the "How"), like for example, the communication structures that senior HCO leaders could establish to "cultivate champions" and facilitate "innovation-values fit" at a unit level. The remainder of this section discusses lessons learned from findings in both types of articles.

\section{Lessons learned on factors driving innovation implementation (retrospective articles)}

The "Innovation Implementation Framework," originally developed by Klein et al in 1996 and refined by Helfrich et al in 2007, was a popular theoretical framework used to explain factors driving innovation implementation success, particularly, in works that sought to retrospectively 
evaluate implementation effectiveness, through surveys and interviews with $\mathrm{HCO}$ leaders and practitioners. ${ }^{16,25}$ Under this framework, complex innovations are those that are perceived as new by the adopting entity and that require active coordinated action by multiple members of the entity, to achieve organizational benefits.

According to the original framework, implementation effectiveness, defined as the quality and consistency of innovation use, results from both perceptions of implementation climate (IC) and organizational implementation policies and practices (IPPs). IPPs refer to the formal strategies used by an organization to put innovations into use, while IC refers to the extent to which members perceive an innovation as being supported and rewarded by the organization. The refined innovation implementation framework by Helfrich et al incorporates six determinants of implementation effectiveness (including IPPs and IC), namely, 1) support from management, 2) availability of financial resource, 3) innovation-values fit, 4) presence of a champion, 5) IPPs, and 6) $\mathrm{IC} .{ }^{25}$

McAlearney et al used the framework developed by Helfrich et al to identify factors explaining implementation of high performance work practices (HPWPs) at five award-winning health care institutions. ${ }^{26,27}$ Although several common themes emerged, the notion of innovation-values fit was found to be a key factor influencing implementation effectives; all the five institutions sought to motivate organizational change by stressing the connection between HPWPrelated innovations and the accomplishment of broader goals and values of the organizations such as improved quality and safety.

Another study by Jacobs et al which applied the Helfrich et al framework among over 400 physician participants in the Community Clinical Oncology Program found that the perception of IC among physicians was a key factor impacting implementation effectiveness (ie, the enrollment of patients in trials by physicians). The results suggested that managers seeking effective implementation of innovations must create an environment that physicians perceive as valuing the innovation and encouraging implementation. In addition, specific IPPs need to be instituted to increase positive perceptions of the IC. In other words, IPPs need to include specific rewards and support for innovation use. ${ }^{28}$

In a similar vein, Weiner et $\mathrm{al}^{29}$ have emphasized the importance of IC as a construct deserving substantial attention in implementation science, in general. Importantly, they emphasized that the IC construct applies most readily to complex innovations requiring coordinated actions and behavior change by multiple members of the organization for implementation success and the realization of anticipated benefits. For innovations that are not complex, they argued that theories of individual behavior change may be more relevant for understanding implementation effectiveness. By articulating the importance of measuring the "IC," they touch upon a recurring theme in the literature, ie, a call for more research to understand the broader contextual factors facilitating or impeding innovation implementation, at the HCO level. ${ }^{29}$

Another theoretical perspective that has been advanced (on innovation implementation) is the middle manager's role in innovation implementation. This work essentially incorporates the role of the middle manager into the Helfrich et al framework to highlight the potential of middle managers in impacting implementation effectiveness. Since middle managers are located between senior executives and frontline staff, they can promote implementation in four ways: 1) diffusion of information, 2) synthesis of information, 3) mediation between strategy and daily activities, and 4) selling of the innovation implementation, which in turn helps bridge the gap between implementation policy and practices and IC to impact implementation effectiveness. ${ }^{30-33}$

Even studies that did not explicitly incorporate the Helfrich et al framework have found support for its components. ${ }^{3441,54}$ For example, Bunting ${ }^{34}$ compared the perceptions of implementation barriers among hospital risk managers by bed size and organizational structure for three innovations: surgical safety checklist, catheter-associated urinary tract infections, and patient- and family-centered care. The study used the "Barriers Scale," to measure barriers related to adoption, organizational, innovation, and communication. Findings suggested that there was minimal value in attempting to identify implementation barriers for specific innovations by bed size and organizational structure. Instead, the results revealed the importance of identifying champions to support each innovation. Champions in turn would play a key role in eliminating unsafe habits and mitigating fear of change among clinicians. Therefore, this research echoed the importance of "presence of a champion," a component in the Helfrich et al framework. It also articulated the need for future research on the role of contextual variables, like culture of patient safety, for innovation implementation. ${ }^{34,54}$

Similarly, André and Sjøvold ${ }^{56}$ used the Systematizing Person-Group Relations framework to compare the factors characterizing the work environment in a hospital unit that successfully implemented change to a unit that was unsuccessful. The framework applies six different dimensions, 
each representing different behavior in a work environment: synergy, withdrawal, opposition, dependence, control, and nurture. The study found that workers in the successful unit exhibited significantly higher synergy and control, pointing to the important role of work environment in innovation implementation. The focus on work environment in this study in turn could be viewed as analogous to the emphasis on "IC" in the Innovation Implementation Framework. ${ }^{56}$

In another study, Sorensen et $\mathrm{al}^{38}$ compared implementation of "low-complexity" innovations like risk assessment systems for pressure ulcers with high-complexity innovations like risk assessment systems for adverse drug events at five hospitals. The study found that participating hospitals were more successful in implementing the low-complexity innovations. The study concluded that facilitating complex innovation implementation would require hospital leaders to allocate sufficient resources and effectively communicate with local champions and users to align innovations with existing workflows and systems. Essentially, this study highlighted the role of innovation attributes as an important contextual variable in impacting innovation implementation and the importance of considering the broader context in implementing complex innovations. ${ }^{38}$

Moving on to articles that sought to retrospectively understand the factors driving innovation implementation at the frontline clinician level, Gupte et al examined implementation of electronic consultations (e-consults) in a Veterans Affairs health care system. The purpose of the e-consult is to enable bidirectional communication between a requesting primary care physician and the requested specialty clinics. The study found not only that e-consults were frequently used for the intended purpose but also that they had been adapted for innovative (unexpected) administrative uses. ${ }^{44}$ The authors use the disruptive innovation framework to discuss the success with innovation implementation in that disruptive usage begins when an innovation is successful among a group of users because it addresses previously unmet needs. However, an implication is that such a framework would apply to innovations that have high perceived utility in the eyes of the clinician and, thereby, are directly aligned with clinician values, which, in other words, translates to high "innovation-values fit."

To corroborate this gleaning, another study illustrates the potential for deskilling and adaptation by clinicians in the absence of "innovation-values fit." Hoff ${ }^{45}$ conducted interviews with primary care physicians in the USA to examine implementation of two innovations, ie, electronic health record use and evidence-based practice guidelines, and found that primary care physicians use these innovations in ways that indicate "deskilling outcomes," including stereotyping of patients and decreasing confidence in clinical decision-making. The pressure to increase patient volume and comply with complex requirements of chronic disease guidelines left several physicians feeling unable to provide the type of holistic patient care that leveraged their full range of clinical knowledge and skills. ${ }^{45}$ The findings highlight the potential for implementation failure when the innovation is not aligned with clinician values. Since physicians play a proactive role in their own deskilling by working around innovations to manage their workdays better, managers could learn from this to play a proactive role in creating contexts to ensure that physicians use innovations in ways that do not undermine professional knowledge.

Other studies have also highlighted the crucial role of "innovation-values fit" in innovation implementation at a clinician level. For example, Flitter et $\mathrm{al}^{46}$ used a grounded theory approach to analyze physician rejection of two highreliability patient safety programs at separate hospitals and found that provider behaviors that were resistant to patientcentric high-reliability processes were traced to providercentric sense-making by physicians. The seminal work by Rogers on innovation diffusion also posits that the perception of relative advantage of an innovation and its alignment with the values of the adopter are key factors in influencing innovation diffusion, thereby reinforcing the findings of the aforementioned works. ${ }^{46,75}$

For hospitals to be successful in managing high-hazard environments, physicians need to be completely integrated into the complex in-hospital teams needed to accomplish this goal. Importantly, a common aspect across many of the works cited above is a call for more research, including prospective study designs, to evaluate ways to overcome physician resistance to innovation implementation and identify strategies based upon the evidence. ${ }^{46,47}$ As such, similar to the calls (noted earlier), among organizational-level retrospective studies on innovation implementation, the clinician-level studies have also called for prospective research to understand how successful behavior change and innovation implementation occur at the clinician level.

\section{Key insights from retrospective articles on innovation implementation}

A common theme among the articles discussed above is that they were all retrospective studies seeking to understand factors driving innovation implementation at the organizational and clinician levels, in hospitals and health systems. At the organizational level, several articles have 
used the Innovation Implementation Framework by Helfrich et al to conduct their inquiries and found support for various components of this framework in driving innovation implementation, including IPP, IC, and innovation-values fit. ${ }^{25-29,36,37}$ Other studies that have used frameworks like the Barriers Scale and Middle Manager's role in innovation implementation have also found support for individual components of the Innovation Implementation Framework, like "presence of a champion" and "support from management." ${ }^{30-34}$ At the clinician level, applications of frameworks like Disruptive Innovation theory, Deskilling and Adaptation, and Sense-Making theory, among others, have helped to demonstrate the crucial role of "innovation-values fit" for enabling behavior change and innovation implementation among frontline clinicians. ${ }^{44-46}$ Also, several retrospective studies have stressed the role of "innovation attributes" as an important contextual variable in understanding implementation success. While this factor is not included in the Innovation Implementation Framework, this framework by itself is intended to be applicable to complex innovations that require coordinated, collective actions and behavior change by multiple members of the organization for implementation success. ${ }^{36-38}$

Importantly, a majority of retrospective studies that sought to understand key drivers of innovation implementation (at both organizational and clinician levels) have also underscored the need for further research to understand the role of contextual factors internal and external to an organization in impacting innovation implementation success. ${ }^{29,34-41}$ In other words, there was an urgent call in this literature for research to explicate how the key drivers of implementation success could be achieved within a given HCO context.

Articles by Ovretveit et al reinforce this call for research, which are dedicated to articulating the need for research to understand the "conditions for improvement," ie, the context in which innovations are successfully implemented. ${ }^{42,43}$ The context refers to all variables that are not part of an innovation implementation intervention. Although research has helped identify factors important for implementation success, we do not know which conditions are significant for implementation success, and if these conditions vary across interventions or whether some conditions are more or less important at different times in carrying out an intervention. Ovretveit et $\mathrm{al}^{43}$ posit that prospective non-experimental theory-based research designs are essential for understanding the conditions that could help increase the pace of improvements and thereby develop the science faster. Therefore, the argument is that prospective research designs may be vital for developing knowledge about the conditions needed for implementing different types of innovations and for making qualified generalizations regarding the conditions that might facilitate or hinder innovation implementation in HCOs. In summary, prospective designs may be vital for understanding the role of contextual factors in innovation implementation.

\section{Lessons learned on how innovation implementation occurs (prospective articles)}

The previous subsection discussed retrospective studies of factors driving (or impeding) innovation implementation at the organizational and clinician levels. In both the sets of studies, there were calls for prospective research to understand the role of contextual factors in enabling implementation success and to identify management strategies for success. Although the review showed a considerably smaller number of prospective studies on innovation implementation in hospitals and health systems, some work has been done to understand how innovation implementation occurs at a hospital/unit level and to develop context-sensitive management strategies based on the evidence.

For example, Rangachari et al used the Professional Complex Systems (PCS) Framework to conduct a 52-week intervention to promote successful implementation of the CLB in two intensive care units (ICUs) at an academic health center. ${ }^{48-52}$ The CLB is a set of five evidence-based practices known to prevent Central Line Associated Bloodstream Infection (CLABSIs). The PCS framework suggests that top-down, periodic, and proactive communications may be effective for exchange of tacit knowledge exchange, learning, and practice change in HCOs. ${ }^{50,76}$ The rationale is that "professional organizations" contain multiple professional subgroups, each differing in shared expertise and value systems. Since each professional subgroup performs a set of actions to achieve the broader goals of the organization, these actions or "subgoals" are reinforced through regular within-group communication. This situation in turn results in the absence of cognitive links across subgoals and between each subgoal and the broader goals of the organization. Therefore, the PCS literature suggests that under conditions of rapid change, senior HCO leaders must make efforts to proactively and periodically communicate, to create cognitive links between subgoals and organizational goals to enable exchange of tacit knowledge across professional subgroups, learning, and practice change.

Both the study units (ICUs) had higher-than-expected CLABSI rates and poor baseline adherence to the CLB. 
Following from the PCS framework, top-down proactive and periodic communications were conducted by senior leaders of the hospital, over a 1-year/52-week period, to promote adherence to the CLB in both the ICUs. Concurrently, the following were examined: 1) structure and content of communication at the unit-level related to the CLB through "communication logs," completed weekly by physicians and nurses in the unit, and 2) outcomes at the unit level, ie, adherence to CLB and rates of CLABSIs. At the end of the study, the two ICUs showed substantially increased CLB adherence and significant reductions in CLABSIs. In the medical ICU, for example, the number of CLABSI declined from 14 per quarter (prior to the intervention) to zero, which was fully sustained over a 2-year period following the intervention. ${ }^{48-51}$

Analysis of unit-level communication dynamics revealed a significant increase in "proactive" risk-reducing communications between physicians and nurses, over time (eg, proactive removal of unnecessary catheters), compared to "reactive" communication of infection prevention protocols among nurses (eg, wear mask before entering patient room) during the initial phase of the study. A closer review showed that during initial phases of the study, "champions" emerged within each ICU in the early stages of the intervention to initiate process improvements (eg, catheter certification, plan-of-care documentation, etc). The increase in proactive risk-reducing communications across physicians and nurses correlated directly with a significant decline in catheter days (or central catheter use) in the study units, over time. In effect, the communication dynamics were indicative of a shared understanding of a new infection prevention tactic in the units, ie, proactive removal of unnecessary central lines. Overall, results showed that proactive top-down periodic communications on evidencebased practices had the potential to enable tacit knowledge exchange across professional subgroups on practice gaps and their consequences to enable a shared understanding of a new way of doing things, ie, successful innovation implementation, leading to significantly improved patient outcomes. ${ }^{49,50}$

Importantly, the study helped identify context-sensitive strategies for successful implementation of change at the hospital unit level. For example, it suggested that each unit must be screened for change champions, and if champions are not found, periodic, proactive top-down communications must be conducted to enable champions to emerge from within each unit to facilitate innovation implementation. The study also found that simply sharing aggregate outcomes data (like infection rates) or even published evidence on effectiveness of CLB was not sufficient to sway clinicians to change practice. On the other hand, clinicians were responsive to process data demonstrating links between practice adherence and patient outcomes (eg, associations between early removal of central lines and reduced incidence of CLABSIs), since this type of data is actionable. The study also pointed to the importance of senior leaders emphasizing the role of communication and teamwork (and providing "communication logs") to facilitate exchange of tacit knowledge related to the CLB across professional subgroups to enable learning and change at the unit level. In summary, the study helped develop strategies for innovation implementation at the organizational, unit, and frontline clinician levels. ${ }^{50}$

In a similar vein, Tucker et $\mathrm{al}^{18}$ conducted a prospective study of how learning occurred in hospital ICUs in the context of new practice implementation. To this effect, they investigated specific learning activities undertaken by project teams while implementing new or improved practices. Data were collected from several neonatal ICUs, which implemented new practices to understand the specific learning activities reported by participants. The study discovered two distinct types of learning activities: learn-what (ie, activities that identify prevailing best practices) and learn-how (ie, activities that helped operationalize best practices in the care setting). While learn-how was positively associated with implementation success, learn-what was not. ${ }^{18}$

\section{Key insights from prospective articles on innovation implementation}

While retrospective studies have helped to identify key drivers of implementation effectiveness (the "What"), like "presence of a champion," "innovation-values fit," etc; prospective studies have provided insights on how these drivers could be attained (the "How"). For example, the works by Rangachari et al have helped shed light on the communication structures that senior hospital leaders could establish to cultivate effective "change champions" and enable "innovation-values fit" at the unit level, to in turn facilitate a shared understanding across professional subgroups of new ways of doing things, to foster success with innovation implementation. ${ }^{48-52}$

The concept of learn-how in the Tucker et al study can be likened to the concept of tacit knowledge discussed in the work by Rangachari et al. ${ }^{18,50}$ Tacit knowledge refers to practice-based knowledge or knowhow. A key tenet of complex systems theory is that organizational change requires organizational learning, which in turn involves the creation of collective tacit knowledge, the most strategically important type of organizational knowledge. ${ }^{77}$ Therefore, a crucial task of managers in complex systems may be to develop mechanisms for creating this type of knowledge. ${ }^{78}$ 
In summary, the prospective studies discussed above suggest that complexity theory and complex systems thinking could be a valuable tool in guiding the design of prospective studies seeking to enable innovation implementation through knowledge exchange and collective learning, to in turn facilitate the identification of context-sensitive strategies for implementation effectiveness. This would be directly responsive to the call in the literature for more theory-based, prospective research designs for understanding the conditions for improvements to further develop the science and provide qualified generalizations regarding the conditions that can enable innovation implementation in HCOs. ${ }^{42,43}$

\section{Strategies for success with innovation implementation in hospitals and health systems}

Retrospective studies have used theoretical frameworks like the Innovation Implementation Framework, Barriers Scale, and Middle Manager's role, among others, to gain insight into key drivers of success in innovation implementation at the organizational level, including 1) support from management, 2) availability of financial resources, 3) innovation-values fit, 4) presence of a champion, 5) IPPs, and 6) IC. At the clinician level, retrospective studies have used variety of frameworks like Disruptive Innovation theory, Diffusion of Innovation, and Sense-Making theory, among others, to demonstrate the crucial role of "innovation-values fit" for enabling behavior change and innovation implementation among frontline clinicians.

On the other hand, the prospective studies on innovation implementation have leveraged the PCS framework to design interventions for successful innovation implementation, by enabling the exchange of tacit (practice-based) knowledge exchange across professional subgroups, to foster collective learning (on gaps in practice and consequences of those gaps), and to facilitate practice change (shared understanding among clinicians of new ways of providing care). In doing so, these studies have helped shed light on how the key drivers of success in innovation implementation (identified by retrospective studies) like "presence of a champion," "innovation-values fit," etc, could be attained. Correspondingly, prospective studies have also helped develop context-sensitive strategies for success with innovation implementation at organizational and clinician levels.

At the organizational level, these efforts provide insight into the structure and content of communication for effective innovation implementation in hospital units. The efforts suggest that top-down proactive periodic communications by senior hospital leaders can enable tacit knowledge exchange across professional subgroups, to enable collective learning and change at the unit level. A key insight from the research is that "awareness does not translate to implementation." Simply providing resources like the vascular access team or educating providers on published evidence related to practice guidelines does not necessarily translate to practice change. Instead, the implementation of new practices (innovation) by clinicians requires champions at the unit level to foster engagement and collective learning of evidence-based practices and implement process changes and protocols, to ensure consistent implementation of those practices at the unit level.

Similarly, at the frontline clinician level, prospective studies have provided context-sensitive evidence-based management strategies for:

1. Creation of implementation champions; champions need to be screening for at the unit level and they are not found; senior leaders must conduct proactive top-down communications to allow champions to emerge from within each unit, to facilitate innovation implementation.

2. Creation of innovation-values fit by enabling tacit knowledge exchange of evidence-based practices (innovation) and practice gaps across professional subgroups to facilitate collective learning on the consequences of practice gaps for quality patient care (clinician value).

3. Creation of clinician engagement in performance measurement by sharing data on process measures versus aggregate outcome measures to highlight gaps in practice and the consequences of those gaps for patient outcomes and safety.

\section{Relevance of management research to innovation implementation in hospitals and health systems}

Both the categories of articles reviewed earlier highlight the substantial relevance of management research for implementation effectiveness in hospitals and health systems. For example, as indicated in Table 1, management research suggests that innovations should be framed as a "learning" challenge to be successful in a health care organizational context. As discussed earlier, prospective studies on innovation implementation took exactly this approach. ${ }^{48-52}$ They leveraged the PCS framework to design an intervention for enabling tacit knowledge exchange across subgroups of professionals, to facilitate collective learning, and practice change, ie, successful implementation of innovations at the unit level. Moreover, these studies were conducted in the form 
of funded pilot research projects within the organizational context, which is in line with another recommendation from management research. ${ }^{18,50}$

Concurrently, the prospective innovation implementation projects comprised elements of transformational leadership style (recommended by management research), wherein senior leaders and champions at the institution played a key role in conducting proactive, periodic communication interventions over a 1-year period to enable tacit knowledge exchange on evidence-based practices across professional subgroups to facilitate collective learning and culture change. As such, by stimulating the workforce to embrace the innovations, leaders helped motivate health professionals to consider how the individual provider's goal of patient care overlaps with collective goal of infection prevention and patient safety. These experiences suggest that the PCS framework may have the potential to serve as a blueprint for operationalizing transformative leadership style.

In addition, management research suggests that organizational identification is increased for physicians when they perceive compatibility between their own values and organizational values. A recurring theme among the retrospective studies reviewed was the importance of "innovation-values fit," ie, alignment between the innovation and clinicians' values in enabling successful innovation implementation at both the organizational and the clinician levels.

Management research also recommends engaging clinicians in performance measurement and improvement. In this regard, prospective studies showed that while clinicians do not pay much attention to aggregate outcome data (like infection rates), they can be engaged through data on process measures which help highlight gaps in practices and the consequences of those gaps on patient outcomes like infections. ${ }^{48-52}$ In summary, a majority of the recommendations from management research summarized in Table 1 were noted as being relevant to the literature on innovation implementation in hospitals and health systems.

\section{Gaps in the literature and future research avenues}

The review reveals the need for more prospective studies to understand the role of contextual factors in innovation implementation, which in turn can help generate context-sensitive strategies for success with innovation implementation. This type of evidence would be needed across a broad spectrum of innovations, varied types of health care settings, and networks of HCOs. Moreover, in keeping with the growing emphasis on "population health," there is a an urgent need for prospective studies on innovation implementation in chronic disease management, to improve care coordination, reduce errors during care transitions, and engage patients in health care delivery.

Importantly, to complement prospective studies on innovation implementation, there is a need for studies on the sustainability of innovations in health care, which is a substantial gap in the literature. Recently, Fleiszer et $\mathrm{al}^{53}$ have emphasized the need for this line of research. They sought to understand how an evidence-based guidelines program in nursing was sustained over the longer term in a larger health system. They found that initial successful implementation of evidence-based practices in the hospital setting does not imply long-term sustainability. ${ }^{53}$ They argue that persistent, committed, and aligned actions from senior leaders in a multitude of roles across a health system may be necessary to ensure long-term sustainability of an evidence-based guidelines program. Despite advances in the field of innovation implementation, far more attention has been focused on understanding how to successfully implement intervention as opposed to the "staying power" of those innovations. We hardly have any empirical evidence related to sustainability of innovations that are successfully implemented in a HCO.$^{53}$ Combining the need for prospective studies on both innovation implementation and the sustainability of health care innovations, one can argue that there is a need for prospective studies on implementing sustainable change across a health system (and networks of health systems), to achieve the triple aim of quality care and population health at lower costs. This would require an integration of management thinking in medicine and health care delivery and bold exploration of the role of health information technology in not only improving the quality and safety of health care delivery, but also promoting the health of populations.

\section{Limitations of the review}

This integrative review of literature was focused on a specialized domain within implementation science pertaining to "innovation implementation" in hospitals and health systems, in the context of quality of health care. Correspondingly, several exclusion criteria were applied to articles; for example, only studies based in hospitals and health systems (as opposed to long-term care, palliative care, behavioral health, home health organizations, etc) were included; only studies pertaining to quality and delivery of health care (as opposed to education or public health) were included, and given the context for the review, only studies based in USA and developed nations were included. Correspondingly, the 
study is limited to understanding the state of the literature on "innovation implementation in hospitals and health systems" within the broader realm of implementation science. Despite these limitations, the review generates significant insights into the distinct contributions of retrospective and prospective studies on innovation implementation. While retrospective studies have helped understand what the key drivers of innovation implementation in hospitals and health systems are, prospective studies have shed light on how these key drivers could be attained. Therefore, both the types of studies have contributed significantly to generating strategies for success with innovation implementation. Since any empirical article within the realm of implementation science could be classified under either of these two categories (retrospective or prospective), this bifurcation could be applied to larger set of empirical articles to gain insights into their distinct contributions to innovation implementation and broader contributions to implementation science. To an extent, therefore, this aspect of the paper also serves to mitigate the limitations emanating from the restricted scope of this paper.

\section{Conclusion}

This integrative review of literature suggests that in addition to being relevant for improving the quality of care, management research can make a direct impact in improving patient outcomes by helping to design successful interventions for innovation implementation in HCOs. The heightened attention to "innovation implementation" over the past decade by research funding agencies like AHRQ and NIH, with support from industry leaders like the IHI and the Joint Commission, has helped to bring health service researchers together with health care managers and practitioners to collaborate on implementation research. These efforts in turn have helped produce catchphrases like "learning organization," "change theory," "systems thinking," among hospital administrators, managers, and practitioners within the health care industry. In 2007, the Academy of Management (AOM) and the IOM came together to discuss how management research might inform the IOM's work, particularly in regard to developing recommendations that could be successfully implemented. ${ }^{79}$ The results of innovation implementation research in hospitals and health systems over the past decade suggest that the AOM-IOM collaboration should be moved to the next level to facilitate translational research, with increased funding support from federal agencies like AHRQ and NIH for more prospective studies not only on implementation effectiveness but also on the sustainability of innovations in HCOs, to further improve the quality and safety of health care delivery and promote population health.

\section{Disclosure}

The author reports no conflicts of interest in this work.

\section{References}

1. Kohn LT, Corrigan JM, Donaldson MS. To Err Is Human: Building a Safer Health System. Washington, DC: National Academies Press; 1999.

2. IHI, Institute for Healthcare Improvement 5 Million Lives Campaign. Available from: http://www.ihi.org/Engage/Initiatives/ Completed/5MillionLivesCampaign/Pages/default.aspx. Accessed July 31, 2017.

3. AHRQ, Agency for Healthcare Research and Quality. 2007 National Healthcare Quality Report. Rockville, MD: Author; 2007.

4. CMS Centers for Medicare \& Medicaid Services Hospital Compare Available from: https://www.cms.gov/medicare/quality-initiativespatient-assessment-instruments/hospitalqualityinits/hospitalcompare. html. Accessed July 31, 2017.

5. Leapfrog Group. Eighty-Seven Percent of US Hospitals Do Not Take Recommended Steps to Prevent Avoidable Infections; 2007. Available from: http://www.hcpro.com/HOM-76404-2912/Leapfrog-87-ofhospitals-dont-have-procedures-to-prevent-infections.html. Accessed July 31, 2017.

6. Nembhard IM, Alexander JA, Hoff TJ, Ramanujam R. Why does the quality of health care continue to lag? Insights from management research. Acad Manage Perspect. 2009;23(1):24-41.

7. Batalden PB, Davidoff F. What is "quality improvement" and how can it transform healthcare? Qual Saf Health Care. 2007;16(1):2-3.

8. Eccles M, Mittman B. Welcome to implementation science. Implement Sci. 2006;1(1): 1 .

9. Bohmer RMJ, Knopp CI. The Challenge Facing the U.S. Healthcare Delivery System (Case No. 9-606-096). Boston: Harvard Business School Publishing; 2007.

10. Ramanujam R, Rousseau DM. The challenges are organizational not just clinical. J Organ Behav. 2006;27(7):811-827.

11. Coye MJ. No Toyotas in health care: why medical care has not evolved to meet patients' needs. Health Affairs. 2001;20(6):44-56.

12. Gilmartin MJ, D'Aunno TA. Leadership research in health care: a review and roadmap. Acad Manag Ann. 2007;1(1):387-438.

13. Bazzoli G, Dynan L, Burns L, Yap C. Two decades of organizational change in health care: What have we learned? Med Care Res Rev. 2004; 61:247-331.

14. Bohmer RMJ. Medicine's service challenge: blending custom and standard care. Health Care Manage Rev. 2005;30(4):322-330.

15. Fleuren M, Wiefferink K, Paulussen T. Determinants of innovation within health care organizations: literature review and Delphi study. Int J Qual Health Care. 2004;16(2):107-123.

16. Klein KJ, Sorra JS. The challenge of innovation implementation. Acad Manage Rev. 1996;21(4):1055-1080.

17. Nembhard IM, Edmondson AC. Making it safe: the effects of leader inclusiveness and professional status on psychological safety and improvement efforts in health care teams. J Organ Behav. 2006;27(7):941-966.

18. Tucker AL, Nembhard IM, Edmondson AC. Implementing new practices: an empirical study of organizational learning in hospital intensive care units. Manage Sci. 2007;53(6):894-907.

19. Bate P, Mendel P, Robert G, editors. Organizing for Quality: The Improvement Journeys of Leading Hospitals in Europe and the United States. Oxford, UK: Radcliffe Publishing; 2007.

20. Edmondson AC. Framing for learning: lessons in successful technology implementation. Calif Manage Rev. 2003;45(2):34-54. 
21. Institute of Medicine. Keeping Patients Safe: Transforming the Work Environment of Nurses. Washington, DC: National Academies Press; 2004.

22. Leape LL, Berwick DM. Five years after "To err is human": what have we learned? J Am Med Assoc. 2005;293(19):2384-2390.

23. Rosenthal MB, Frank RG, Li Z, Epstein AM. Early experience with pay-for-performance: from concept to practice. $N$ Engl J Med. 2005; 294(14):1788-1793.

24. Barker JR. Tightening the iron cage: concertive control in self-managing teams. Admin Sci Quart. 2003;38:408-437.

25. Helfrich CB, Weiner BJ, McKinney MM. Determinants of implementation effectiveness: adapting a framework for complex innovations. Med Care Res Rev. 2007;64(3):279-303.

26. McAlearney AS, Robbins J, Garman AN, Song P. Implementing highperformance work practices in healthcare organizations: qualitative and conceptual evidence. J Healthc Manag. 2013;58(6):446-452.

27. McAlearney AS, Walker DM, Livaudais-Toman J, Parides M, Bickell NA. Challenges of implementation and implementation research: learning from an intervention study designed to improve tumor registry reporting. SAGE Open Med. 2016;4:1-8.

28. Jacobs SR, Weiner BJ, Reeve BB, Hoffman DA, Christian M, Weinberger $\mathrm{M}$. Determining the predictors of innovation implementation in healthcare: a quantitative analysis of implementation effectiveness. BMC Health Serv Res. 2015;15:6.

29. Weiner BJ, Belden CM, Bergmire DM, Johnston M. The meaning and measurement of implementation climate. Implement Sci. 2011;6:78.

30. Birken SA, Daniel-Lee SY, Weiner BJ. Uncovering middle managers' role in healthcare innovation implementation. Implement Sci. 2012;7:28

31. Birken SA, DiMartino LD, Kirk MA, Lee SY, McClelland M, Albert NM. Elaborating on theory with middle managers' experience implementing healthcare innovations in practice. Implement Sci. 2016;11:2.

32. Birken SA, Daniel-Lee SY, Weiner BJ, Shin MH, Chiu M, Schaefer CT. From strategy to action: how top managers' support increases middle managers' commitment to innovation implementation in healthcare organizations. Health Care Manage Rev. 2015;40(2):159-168.

33. Chuang E, Jason K, Morgan JC. Implementing complex innovations: factors influencing middle manager support. Health Care Manage Rev. 2011;36(4):369-379

34. Bunting RF. Healthcare innovation barriers: results of a survey of certified professional healthcare risk managers. J Healthc Risk Manag. 2012;31(4):3-16.

35. Barnett J, Vasileiou K, Djemil F, Brooks L, Young T. Understanding innovators' experiences of barriers and facilitators in implementation and diffusion of healthcare service innovations: a qualitative study. BMC Health Serv Res. 2011;11:342.

36. Urquhart R, Porter GA, Sargeant J, Jackson L, Grunfeld E. Multi-level factors influence the implementation and use of complex innovations in cancer care: a multiple case study of synoptic reporting. Implement Sci. 2014;9:121

37. Urquhart R, Sargeant J, Grunfeld E. Exploring the usefulness of two conceptual frameworks for understanding how organizational factors influence innovation implementation in cancer care. $J$ Contin Educ Health Prof. 2013;33(1):48-58.

38. Sorensen AV, Harrison MI, Kane HL, Roussel AE, Halpern MT, Benard SL. From research to practice: factors affecting implementation of prospective targeted injury detection systems. BMJ Qual Saf. 2011;20(6):527-533.

39. Donahue KE, Halladay JR, Wise A, et al. Facilitators of transforming primary care: a look under the hood at practice leadership. Ann Fam Med. 2013;11:S27-S33.

40. Bingham D, Main EK Effective implementation strategies and tactics for leading change on maternity units. J Perinat Neonatal Nurs. 2012;24(1):32-42.

41. Chreim S, Willaims BE, Coller KE. Radical change in healthcare organizations; mapping transitions between templates, enabling factors, and implementation process. J Health Organ Manag. 2012;26(2):215-236.
42. Ovretveit J. Understanding the conditions for improvement: research to discover which context influences affect improvement success. $B M J$ Qual Saf. 2011;20(Suppl 1):i18ei23.

43. Ovretveit J, Andreen-Sachs M, Carlsson J, et al. Implementing organizational and management innovations in Swedish healthcare: lessons from comparisons of 12 cases. J Health Organ Manag. 2012;26(2):237-257.

44. Gupte G, Vimalananda V, Simon SR, DeVito K, Clark J, Orlander JD. Disruptive innovations: implementation of electronic consultations in a veterans affairs healthcare system. JMIR Med Inform. 2016;4(1):e6.

45. Hoff T. Deskilling and adaptation among primary care physicians using two work innovations. Health Care Manage Rev. 2011;36(4):338-348.

46. Flitter MA, Riesenmy KR, Van Stralen D. Current medical staff governance and physician sense-making: a formula for resistance to high reliability. Adv Healthc Manag. 2012;13:3-28.

47. Luiking ML, Aarts L, Bras L, Grypdonck M, Linge RV. Planned change or emergent change implementation approach and nurses' professional clinical autonomy. Nurs Crit Care. 2017;22(6):372-381.

48. Rangachari P. Knowledge sharing and organizational learning in the context of hospital infection prevention. Qual Manag Health Care. 2010;19(1):34-45.

49. Rangachari P, Rissing P, Rethemeyer RK. Awareness of evidencebased practices alone does not translate to implementation: insights from implementation research. Qual Manag Health Care. 2013; 22(2):117-125.

50. Rangachari P, Madaio M, Rethemeyer RK, et al. The evolution of knowledge exchanges enabling successful practice change in two intensive care units. Health Care Manage Rev. 2015;40(1):65-78.

51. Rangachari P, Madaio M, Rethemeyer RK, et al. Cumulative impact of periodic top-down quality improvement communications on infection prevention practices \& outcomes in two units. Health Care Manage Rev. 2015;40(4):324-336.

52. Rangachari P. Role of social knowledge networks in facilitating meaningful use of electronic health record medication reconciliation. J Hosp Admin. 2016;5(3):98-106.

53. Fleiszer AR, Semenic SE, Ritchie JA, Richer MC, Denis JL. An organizational perspective on the long-term sustainability of a nursing best practice guidelines program: a case study. BMC Health Serv Res. 2015;15:535.

54. Funk SG, Champagne MT, Wiese RA, Tornquist EM. BARRIERS: the barriers to research utilization scale. Appl Nurs Res. 1991;4:39-45.

55. Allen JD, Towne SD Jr, Maxwell AE, et al. Measures of organizational characteristics associated with adoption and/or implementation of innovations: a systematic review. BMC Health Serv Res. 2017;17(1):591.

56. André B, Sjøvold E. What characterizes the work culture at a hospital unit that successfully implements change - a correlation study. BMC Health Serv Res. 2017;17(1):486.

57. Harris M, Lawn SJ, Morello A, et al. Practice change in chronic conditions care: an appraisal of theories. BMC Health Serv Res. 2017; 17(1): 170 .

58. Mudumbai SC, Walters TL, Howard SK, et al. The Perioperative Surgical Home model facilitates change implementation in anesthetic technique within a clinical pathway for total knee arthroplasty. Healthcare. 2016;4(4):334-339.

59. Ireland AM. Leading change: implementation of a new care coordination model. Oncol Nurs Forum. 2016;43(3):278-280.

60. Johnson EE, Simpson AN, Harvey JB, Simpson KN. Bariatric surgery implementation trends in the USA from 2002 to 2012. Implement Sci. 2016;11:21

61. Spaulding A, Kash BA, Johnson CE, Gamm L. Organizational capacity for change in health care: development and validation of a scale. Health Care Manage Rev. 2017;42(2):151-161.

62. Bareil C, Duhamel F, Lalonde L, et al. Facilitating implementation of interprofessional collaborative practices into primary care: a trilogy of driving forces. J Healthc Manag. 2015;60(4):287-300.

63. Weberg D, Weberg K. Seven behaviors to advance teamwork: findings from a study of innovation leadership in a simulation center. Nurs Admin Quart. 2014;38(3):230-237. 
64. Cood J. Implementation of a patient-held urinary catheter passport to improve catheter management, by prompting for early removal and enhancing patient compliance. J Infect Prevent. 2014;15(3):88-92.

65. Farley K, Thompson C, Hanbury A, Chambers D. Exploring the feasibility of conjoint analysis as a tool for prioritizing innovations for implementation. Implement Sci. 2013;8:56.

66. Hunt DL, Berg GM, Zackula RE, et al. Treatment provider is most predictive of ED dismissal in minimally-injured trauma patients: a retrospective review. J Trauma Manag Outcomes 2013;7(1):5.

67. Allegranzi B, Sax H, Pittet D. Hand hygiene and healthcare system change within multi-modal promotion: a narrative review. J Hosp Infect. 2013;83(Suppl 1):S3-S10.

68. Löfgren S, Hansson J, Øvretveit J, Brommels M. Context challenges the champion: improving hip fracture care in a Swedish university hospital. Int J Health Care Qual Assur. 2012;25(2):118-133.

69. Hansson J, Tolf S, Øvretveit J, Carlsson J, Brommels M. What happened to the no-wait hospital? A case study of implementation of operational plans for reduced waits. Qual Manag Health Care. 2012;21(1):34-43.

70. Jeskey M, Card E, Nelson D, et al. Nurse adoption of continuous patient monitoring on acute post-surgical units: managing technology implementation. J Nurs Manag. 2011;19(7):863-875.

71. Luiking ML, van Linge R, Bras L, Grypdonck M, Aarts L. Intensive insulin therapy implementation by means of planned versus emergent change approach. Nurs Crit Care. 2016;21(3):127-136.
72. Weiner BJ, Amick H, Lee SY. Conceptualization and measurement of organizational readiness for change: a review of the literature in health services research and other fields. Med Care Res Rev. 2008;65(4): 379-436.

73. Walker DM, Hefner JL, Sova LN, Hilligoss B, Song PH, McAlearney AS. Implementing accountable care organizations: lessons from a qualitative analysis of four private sector organizations. $J$ Healthc Manag. 2017;62(6):419-431.

74. Bunger AC, Lengnick-Hall R. Do learning collaboratives strengthen communication? A comparison of organizational team communication networks over time. Health Care Manage Rev. 2018;43(1):50-60.

75. Rogers E. Diffusion of Innovations. New York: Free Press of Glencoe.

76. Anderson A, McDaniel R. Managing health care organizations: professionalism meets complexity science. Health Care Manage Rev. 2000;25(1):83Y92.

77. Plsek P. Redesigning health care with insights from the science of complex adaptive systems (Appendix B, 309Y322). In: Institute of Medicine, editor. Crossing the Quality Chasm. Washington, DC: National Academies Press.

78. Spender J. Making knowledge the basis of a dynamic theory of the firm. Strateg Manag J. 1996;17:45Y62.

79. Academy of Management Scholars. Applying Organizational Research and Theory to Institute of Medicine Reports: A Review of Three IOM Reports. Briarcliff Manor, NY: Academy of Management.
Innovation and Entrepreneurship in Health

\section{Publish your work in this journal}

Innovation and Entrepreneurship in Health is an international, peer reviewed, open access journal publishing original research, reports, reviews and commentaries on innovation and entrepreneurship in health. Special focus will be given to the theory, process, and practice of innovation and entrepreneurship by individuals and organizations

\section{Dovepress}

within the health care context globally. The manuscript managemen system is completely online and includes a very quick and fair peer review system, which is all easy to use. Visit http://www.dovepress.com testimonials.php to read real quotes from published authors. 